\title{
Sentimentos mediados: Sensacionalista produz narrativas de risos e discordâncias sobre o Caso Charlie Hebdo ${ }^{1}$
}

\section{Maria das Graças Pinto Coelho, Lídia Raquel Herculano Maia e Afra de Medeiros Soares}

\section{Resumo}

0 texto reflete constructos argumentativos do site humorístico Sensacionalista a respeito da tragédia vivida pelo satírico jornal francês Charlie Hebdo em janeiro de 2015. Acontecimento trágico que redundou em uma série de reflexões sobre narrativas de risos. Assim, o corpus surge em uma pesquisa qualitativa, tendo como foco principal a observação dos comentários em duas postagens do Sensacionalista sobre 0 assunto. Conclui que as bifurcações na produção de sentidos - relato jornalístico associado a emoções, humor, ódio e estranhamentos cognitivos permitem a circulação de diferentes narrativas sobre um mesmo tema e que a sociação apresenta-se na discordância ou na sociabilidade entre pares.

\section{Palavras-Chave}

Bifurcação de Sentidos. Sensacionalista. Charlie Hebdo.

\section{Maria das Graças Pinto Coelho}

I gpcoelho8@gmail.com

Doutora em Educação pela Universidade Federal do Rio Grande do Norte - UFRN, Brasil. Realizou Pós-doutorado no Programa de Pós-Graduação em Comunicação e Cultura da Universidade Federal do Rio de Janeiro - UFRJ, Brasil. Coordena o Grupo de Estudos da Mídia - GEMINI e 0 Programa de Pós-Graduação em Estudos da Mídia da UFRN. É professora do Programa de Pós-Graduação em Educação na mesma instituição.

\section{Lídia Raquel Herculano Maia}

I lidiaraquel2009@hotmail.com

Doutoranda em Comunicação pela Universidade do Vale do Rio dos Sinos - UNISINOS, Brasil. Mestre pelo Programa de Pós-Graduação em Estudos da Mídia da UFRN.

Afra de Medeiros Soares I afra.medeiros@gmail.com Mestre pelo Programa de Pós-Graduação em Estudos da Mídia da UFRN. Professora Substituta do Curso de Produção Cultural do Instituto Federal do Rio Grande do Norte - IFRN.

\section{Notas Introdutórias}

Em uma época em que os dispositivos de produção e veiculação de formas simbólicas tornam-se cada vez mais acessíveis para todos, quaisquer novos acontecimentos resultam em uma infinidade de narrativas, postas em circulação por diferentes grupos sociais. Tal curso narrativo incrementa 0 fluxo interacional em rede, protagonizado por atores sociais, agora representados por identidades cada vez mais complexas e por novos modos de interações que surgem na ambiência digital. A interação entre esses atores, que pressupõe a presença dos objetos digitais nas relações sociais, se acirra, e diferentes sentimentos e emoções passam a ser mediados em redes sociodigitais. Assim, surgem novas formas de interpretação dos acontecimentos que incidem em narrativas de ódio, ressentimento, raiva e preconceito, mas também de delírio, humor e comicidade. Desloca-se, sobremaneira, o papel de interpretação dos acontecimentos sociais, que normalmente era desempenhado pelos meios de comunicação de massa, quando eles tinham 0 monopólio da fala. 0 que não quer dizer que eles deixaram de efetuar tais operações interpretativas, 
codificando significados, mas agora as fazem em paralelo a outras narrativas que emergem socialmente e são negociadas na medida em que as pessoas se apropriam dos artefatos digitais e põem em circulação uma infinidade de sentidos sobre quaisquer acontecimentos.

Foi o que aconteceu com as narrativas que reportaram 0 atentado terrorista ao satírico jornal francês Charlie Hebdo, ocorrido no dia 07 de janeiro de 2015, que provocou a morte de 12 pessoas, entre eles, cartunistas reconhecidos mundialmente. As formas simbólicas se fragmentaram em relatos socialmente compartilhados sobre política, comportamento, estética, crenças e ideologias, provocando inúmeros e intensos debates sobre os vários ângulos que envolveram os fatos. Assim, grupos religiosos se ergueram para discutir os dogmas da fé em questão - nesse caso, o islamismo; 0 campo da mídia aproveitou a oportunidade para defender 0 direito de liberdade de expressão -, algumas vezes se confundindo com o direito de opinião publicada; grupos pacifistas de todo o mundo buscaram reafirmar seus valores; o campo da ciência se lançou para discutir, entre outras hipóteses, a imanência, as causas e consequências do fato, e os setores de entretenimento - em especial, do humor clamaram pelo exercício da comicidade livre de sanções morais e religiosas, independentemente de que pessoas se sintam agredidas na sua fé.
Para além dos espaços de discussão instituídos (midiático, religioso, comportamental e político), acontece também a ocupação de ambientes digitais, formando "bordas" argumentativas sobre 0 caso. Assim, páginas de redes e mídias sociais, sites e portais são transformados em espaços de luta simbólica pelo monopólio do sentido. Humor; liberdade de expressão; a dor e o medo do povo francês, nacionalidade naquele momento ameaçada pelos terroristas; 0 sofrimento dos estrangeiros mulçumanos na Europa, alvos constantes de críticas à sua fé; a hipocrisia de alguns líderes mundiais que receitam liberdades e ao mesmo tempo oprimem Nações e a defesa da religião frente à intolerância - todas essas questões formaram um "caldeirão discursivo", em que múltiplos liames são dissecados por diversos públicos em distintas arenas. Dentre essas arenas, ocupadas pelos internautas para discutir sobre 0 atentado ao Charlie Hebdo, destacamos o site humorístico brasileiro Sensacionalista, que realiza uma espécie de paródia do jornalismo praticado por alguns veículos da imprensa. 0 site produz postagens cômicas, simulando 0 modus operandi do jornalismo convencional, para criticar e, algumas vezes, até debochar de acontecimentos e situações da vida social. Assim se expuseram logo após a tragédia ocorrida no satírico jornal francês. No mesmo dia do atentado, foi postada a "matéria": "Massacre de Paris será feriado mundial do 'Dia do Limite do Humor'”' e, no dia seguinte, postaram outra com o título 
"LUTO: turistas em Paris estão tirando fotos a meio-pau de selfie"3. Essas postagens geraram reações diversas no público leitor, desde os que escrevem sem compreender que a publicação é uma paródia, até os que apoiam o uso do humor nessa situação. E também surgiram os leitores de oposição, que criticaram fervorosamente o uso de tal recurso diante de uma tragédia.

Nossa leitura sobre a repercussão das postagens do site é simpática à ideia do despertar da cócega cognitiva. Valores, dimensões socioculturais e aspectos político-ideológicos, construídos na conversação de formas complexas e, em certa medida, oblíquas, às vezes com conotações degradadas, também significam gostos e afetos compartilhados. Essa troca pode gerar outra forma de interação cognitiva, como parte da dinâmica do riso, que se encontra e se sobrepõe na complexidade argumentativa. 0 Sensacionalista narra assim, sem, contudo, conduzir ao ridículo o povo francês ou as vítimas do atentado. Durante o período observado, vimos o modo pelo qual as pessoas se engajavam no luto e também refletimos sobre a impossibilidade de se estabelecer parâmetros para se aferir limites ao humor em acontecimentos que envolvem disputas políticas, cognitivas, ideológicas e comportamentais.

\section{Notas sobre o método}

Na observação, procuramos nuances argumentativas e bifurcações de sentidos sobre 0 caso Charlie Hebdo, acionadas no âmbito dos comentários, a partir das postagens cômicas do Sensacionalista. Para alcançar tal objetivo, exploramos uma pesquisa qualitativa com a perspectiva da "abordagem etnometodológica do discurso" (BRAGA, A.; RODRIGUES, 2014). A partir da coleta e observação das conversações, engendradas no espaço destinado aos comentários, organizamos categorias de análise com base nas recorrências discursivas evidenciadas nos argumentos postados pelos comentaristas do site Sensacionalista. A coleta dos dados resultou em uma amostra de 88 comentários, os quais foram organizados em três categorias de análise. Tendo em vista que os comentários decorrem de uma narrativa postada pelos gerenciadores do site, buscamos observar também os recursos humorísticos utilizados nas postagens em questão, com base nas classificações cômicas instituídas por Propp (1992).

A etnometodologia não é um método de pesquisa, mas um conjunto de procedimentos que permite ao pesquisador adentrar o contorno do objeto para encarar o entorno da realidade social construída pelos atores. Essa abordagem não

SENSACIONALISTA. Massacre de Paris será feriado mundial do 'Dia do Limite do Humor'. Postado em 07 jan. 2015. Disponível em: <http://sensacionalista.uol.com.br/2015/01/07/massacre-de-paris-sera-feriado-mundial-do-diadolimite-do-humor/>. Acesso em 20 jan. 2015.

LANNA, L. Sensacionalista. LUTO: turistas em Paris estão tirando fotos a meio-pau de selfie. Disponível em: $<$ http://sensacionalista.uol.com.br/2015/01/08/luto-turistas-em-paris-estao-tirando-fotos-a-meio-pau-deselfie/>. Acesso em 20 jan. 2015. Antes disso, lançamos 0 aporte teórico de Simmel $(1983 ; 2006)$ para, a partir de então, discutir as dinâmicas de sociabilidade e conflito que se fazem presentes no âmbito dos comentários online. 
contempla as interações discursivas apenas como algo complementar ao sentido do que é dito. Preocupa-se, antes, em balizar 0 sentido relacionado ao contexto interacional em que as trocas são efetuadas. Afirmamos, então, que a observação do Sensacionalista não privilegia apenas 0 discurso emitido, mas o modo pelo qual ele se entrecruza com outros em contextos de conversação social. Essa abordagem nos auxiliou na análise do corpus, ao passo que nos direcionou na construção da observação, sem partir de um a priori. Observamos em tempo real quais as estratégias, as práticas e os valores que eram acionados pelos comentaristas no processo de conversação.

\section{A política dos comentaristas e as dinâmicas de sociabilidade online}

Não raro, se ouvem relatos sobre quão raivosos e conflituosos podem ser os comentários que circulam na internet, sobretudo em assuntos que mobilizam paixões sociopolíticas, culturais e crenças, o que, de fato, é verdade. Entretanto, é preciso ressaltar que a possibilidade de cada pessoa expor outros pontos de vista sobre 0 assunto abordado também ajuda na reconstrução das narrativas. Ao nos depararmos com os comentários postados por outros internautas, principalmente se estamos inflexionando o humor, ou a cócega cognitiva, podemos ser despertados para questões que não tínhamos atentado durante a leitura ou assistência do enunciado inicial.
Assim, através de conversações informais na internet, não apenas os sentidos sobre uma mesma questão podem ser ampliados, bem como relações de sociabilidade e conflito online podem ser formadas. Com relação ao conceito de sociabilidade, Simmel (2006) introduz a explicação lembrando que são os interesses e as necessidades que movem os sujeitos em direção ao ato de sociação. Esses objetivos materiais que nos direcionam a interagir, formando assim a sociedade, não são, contudo, sociais por si mesmos. São antes fatores de sociação, que pode ser entendida como a forma na qual, por diversas maneiras, os indivíduos se agrupam, formando uma unidade, um tecido social por meio do qual são alcançados determinados objetivos (SIMMEL, 2006).

Progressivamente, na complexidade das relações em sociedade, essas formas originadas em função de objetivos são alteradas, a ponto que, em determinado momento, a sociação se desvencilha do aspecto material, do serviço à vida, ligando-se intimamente ao objeto, formado exclusivamente para seu próprio funcionamento. Quando isso ocorre, vemos surgir o fenômeno da sociabilidade, que seria a forma autônoma ou lúdica da sociação (SIMMEL, 2006;1983).

Na sociabilidade, a existência social adquire sentido próprio, livre de todos os conteúdos materiais. 0 estar juntos adquire força, independentemente do emaranhado com a vida prática, e não por causa dela. Maffesoli (2000), ao se dedicar ao estudo das tribos urbanas 
contemporâneas, compartilha das mesmas ideias de Simmel (2006) e se refere à sociabilidade como um valor em si, afirmando que é o próprio fato de estar junto que prevalece em detrimento do objetivo que se deseja atingir. Não que os grupos sejam vazios de finalidades, elas ainda persistem, mas apenas deixam de ter papel preponderante para a manutenção do agrupamento. Para esse autor, estamos assistindo a um reencantamento do mundo; nesse contexto, a comunicação verbal e não verbal desempenha papel de destaque, sendo responsável pela constituição da vasta rede que liga os indivíduos entre si e estrutura a realidade social (MAFFESOLI, 2000). Não obstante, "logo que a discussão se torna objetiva, não é mais sociável" (SIMMEL, 2006, p.75). Se o conteúdo (girando em torno da fundamentação de uma verdade, por exemplo) torna-se seu fim, desponta, então, uma outra forma de sociação, a saber, o conflito. Quando ele prevalece, o limiar da sociabilidade é rompido.

No caso estudado neste artigo, observamos que 0 conflito é o principal fator de sociação.

A sociabilidade também está presente entre os comentaristas do site, ela ocorre entre aqueles que concordam com as postagens e estabelecem conversas pelo simples prazer de falar ou de expandir a comicidade proposta. Já entre aqueles que incitam o conflito, busca-se estabelecer uma verdade central sobre determinadas nuances da narrativa, ocasionando, assim, um intenso combate argumentativo de ideias divergentes a respeito do atentado em questão. No entanto, Simmel (1983, p.122) defende que o conflito contém algo de positivo, sendo também "um modo de conseguir algum tipo de unidade". 0 autor esclarece ainda que 0 consenso e 0 dissenso não são excludentes, são forças que operam conjuntamente na formação da sociedade.

Portanto, ainda que muitos internautas recorram continuamente ao "fetiche da afirmação" (SENNET, 2012) - que seria 0 ímpeto de insistir num mesmo argumento como se 0 seu conteúdo fosse 0 mais importante do mundo -, esse debate conflituoso acaba pondo em circulação múltiplos liames sobre um mesmo caso, como pudemos constatar nas respostas endereçadas às postagens do Sensacionalista com relação ao atentado contra o Charlie Hebdo. Isso porque os que discordavam da abordagem do ataque ao semanário em tom cômico parecem que se viam no dever de emitir outros argumentos para contrapor o que fora exposto nas postagens do site e assim "ajudar" os pares a terem outras visões sobre a mesma questão. Mas, antes de passarmos à discussão sobre esses comentários, apresentamos a seguir a análise das categorias cômicas presentes no site Sensacionalista, em especial nas duas postagens tomadas como recorte para a pesquisa.

\section{Análise das categorias cômicas: mentira e paródia}

Ao ler o material que deu origem aos comentários analisados no presente artigo, observamos, a partir da classificação de Propp (1992), que a predominância da comicidade construída pelo site Sensacionalista está pautada em duas 
categorias: a mentira cômica e a paródia ${ }^{4}$. Já no próprio subtítulo do site, o slogan/a expressão "isento de verdade" explicita que o conteúdo veiculado naquele espaço, apesar de apresentar características habituais de notícias jornalísticas, não deve ser confundido com a realidade.

Para Propp (1992), existem dois tipos de mentira cômica. A primeira consiste na tentativa de um impostor enganar seu interlocutor, passando a

mentira por verdade, mas precisa ser desmascarada e só será risível se for de pequena monta, sem consequências trágicas. 0 segundo tipo de mentira cômica não tem o propósito de enganar, é contada exclusivamente no intuito de divertir com a insinuação. Nos textos produzidos pelo Sensacionalista, são mais comuns mentiras cômicas do segundo tipo, pois o riso é suscitado com a

\section{LUTO: turistas em Paris estão tirando fotos a meio-pau de selfie}

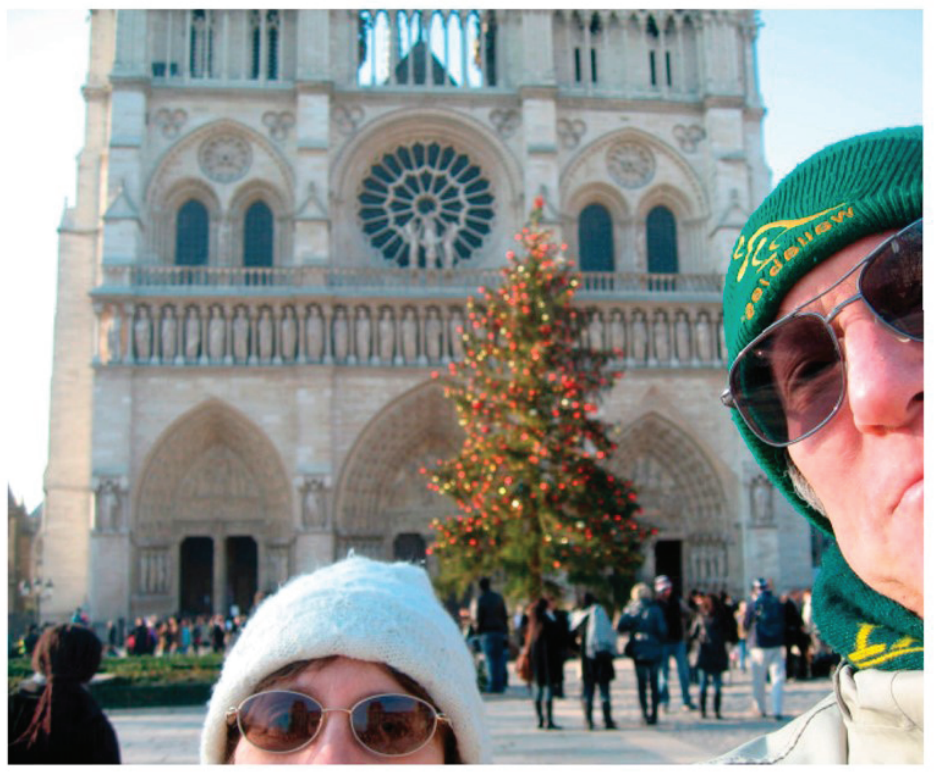

Uma homenagem curiosa e bem humorada vem sendo feita pelos turistas que estão passeando por Paris. Após o presidente François Hollande decretar luto nacional e bandeiras a meio-pau pelas vítimas do atentado à redação do Charlie Hebdo, os turistas também resolveram prestar suas homenagens tirando fotos a meio-pau de selfie. "Foi uma forma que encontramos de prestar o luto, sem perder a beleza dessa cidade. Acho que eles iam gostar da brincadeira", afirmou o turista brasileiro Vicente Salgado. Por causa da meia distância do pau de selfie, o enquadramento não fica lá essas coisas. Mas o que vale é a homenagem.

L.Lanna

Em seu estudo sobre as causas do riso e da comicidade, Propp (1992) sistematizou as formas de indução ao humor a partir de vinte categorias, organizadas por ele mediante a observação de um vasto material científico e popular sobre 0 assunto. Para maiores explicações sobre o método e as categorias elaborados por Propp (1992), ver livro Comicidade e riso. 
compreensão de que se trata de notícias inverídicas. No site, a mentira apropria-se do tom corriqueiro dos textos jornalísticos, produzindo um aparente efeito de verossimilhança, o que se configura risível aos olhos do leitor que entende o seu real propósito.

Como segunda categoria cômica identificada com frequência no site, temos a paródia. A paródia consiste na imitação das características exteriores de um fenômeno qualquer, ocultando ou negando o sentido interior do que é imitado. Podem ser parodiados desde movimentos e gestos a hábitos de uma profissão ou jargões profissionais. No caso do Sensacionalista, a paródia está representada no uso do padrão convencional de construção de notícias, como a presença de um título e a edição do texto jornalístico.

A mentira e a paródia são categorias recorrentes, as quais podem ser encontradas em todas as publicações escritas pelo Sensacionalista.

Entretanto, não são as únicas utilizadas na construção da comicidade a que ele se propõe. Nos dois exemplos a seguir, escolhidos para análise por tratar da tragédia envolvendo o Charlie Hebdo, podemos identificar outros tipos de comicidade, que ocorrem de modo secundário.

Na postagem anterior, podemos identificar, além das categorias principais já descritas, mais duas categorias estabelecidas por Propp (1992): 0 alogismo e os instrumentos linguísticos. A primeira diz respeito à comicidade que nasce a partir da estupidez, da tolice e da incapacidade mais elementar de observar corretamente a causa e 0 efeito de suas atitudes. No exemplo, o alogismo já é esboçado a começar pelo título da "notícia", que associa a expressão luto, um sentimento de tristeza e recolhimento ocasionado por morte, a um suposto comportamento demonstrado por turistas que visitam Paris. No decorrer da notícia, é estabelecida a relação entre 0 luto decretado pelo presidente francês em virtude do atentado à redação do jornal Charlie Hebdo e 0 ato dos turistas de tirarem fotos utilizando 0 acessório popularizado como pau de selfie, que é descrito como uma maneira de homenagear as vítimas.

0 alogismo cômico é também realçado pela presença da categoria instrumentos linguísticos. Os instrumentos são os jogos de palavras, os trocadilhos, os paradoxos e as tiradas bem-humoradas de todo tipo, bem como algumas formas de ironia. É a comicidade representada a partir do uso da língua para produzir riso e zombaria. Ao utilizar a expressão a meio-pau de selfie, a postagem constitui o risível por meio do jogo de palavras, aproximando o sentido do pau que serve de acessório para máquinas fotográficas ao do mastro da bandeira. Neste caso, o hábito de posicionar a bandeira a meio-pau em situações de luto ou protesto é reapropriado pelo primeiro objeto, assumindo características dele.

Já no exemplo a seguir, além da mentira e da paródia, a notícia apresenta como categoria 


\section{Massacre de Paris será feriado mundial do "Dia do Limite do Humor"}

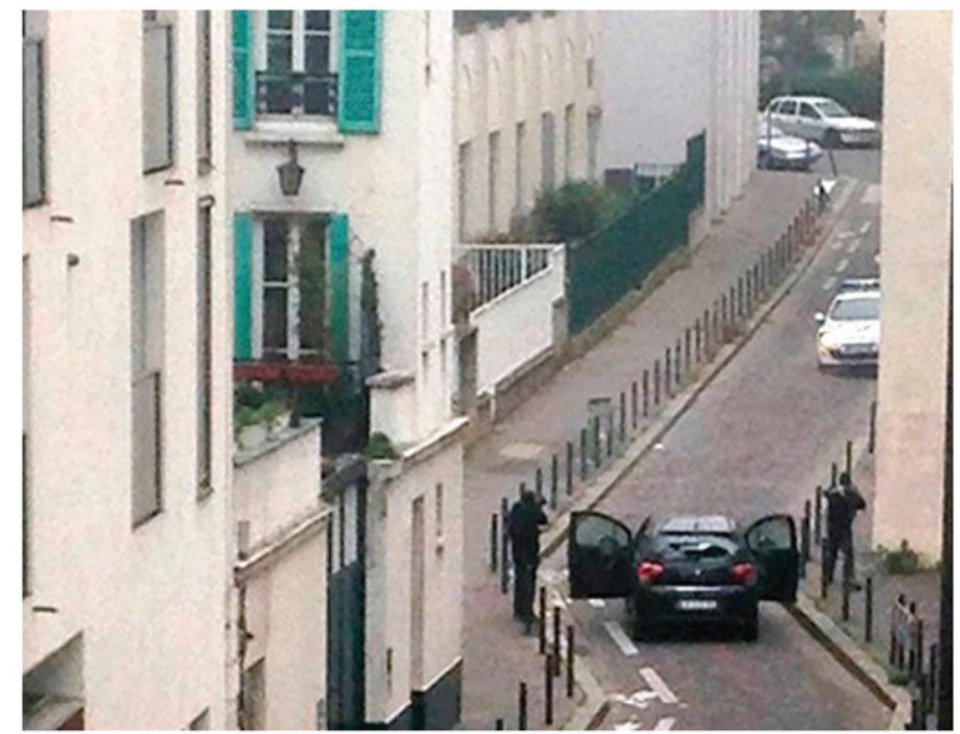

Defensores do limite do humor ganharam uma data para comemorar. Após a morte de 12 pessoas num ataque em Paris, o dia 7 de janeiro será o Dia Mundial do Limite do Humor. Nesse dia não será possivel fazer qualquer piada sobre nada. A Associação dos Politicamente Corretos comemorou a criação do feriado. "É um bom dia para a gente refletir até onde deve ir o humor, pois todo mundo sabe que isso deve ter limites. Já estava na hora de isso ficar bem claro", afirmou o diretor da entidade, Valdineu Pereira.

Uma comissão julgadora será formada para avaliar que piadas podem ou não ser feitas. Resta saber como essa comissão será escolhida. "Será um conselho de sábios, gente que tem ciência do que é bom ou não para a sociedade". A associação dos humoristas não quis se pronunciar, com medo de novos atentados.

\section{Fonte: SENSACIONALISTA, 2015 (Online)}

cômica novamente os instrumentos linguísticos.

Entretanto, nessa publicação, 0 instrumento que suscita o risível é a ironia presente já no título da notícia com a expressão "Dia do Limite do Humor". 0 texto relata ironicamente a suposta instituição de uma data comemorativa ao limite do humor, que seria 07 de janeiro, dia em que ocorreu 0 atentado ao jornal Charlie Hebdo. A morte de 12 pessoas relacionadas ao veículo, conhecido por produzir charges consideradas politicamente incorretas, trouxe à tona debates recorrentes sobre este tipo de humor. 0 site Sensacionalista utiliza a

ironia para ressaltar a subjetividade expressa nas tentativas de discussão sobre 0 tema e para criticar a possibilidade de uma resposta definitiva a respeito do assunto.

Essa segunda postagem mencionada foi a que mais gerou repercussão entre os leitores do site. Do total de 88 comentários observados, 70 referem-se ao post sobre 0 suposto feriado para 0 "Dia Mundial do Limite do Humor". Isso porque a discussão proposta pelo site, sobre 0 
quão risível seria instituir limites ou parâmetros que regulem a indução da comicidade, tornouse objeto de conflituosos debates entre os comentaristas: alguns concordando de pronto e elogiando a crítica aos "politicamente corretos" e outros apelando para o respeito ao outro como parâmetro moral para o uso do humor. A própria postagem do Sensacionalista, tendo como pano de fundo a tragédia ocorrida em Paris, também foi alvo de debates, ao passo que, para muitos, a dor e 0 sofrimento francês não poderiam de modo algum estar envoltos em quaisquer manifestações cômicas. Já para outros, o humor realizado pelo Sensacionalista estaria, naquele momento, se assimilando à criticidade proposta pelo Charlie Hebdo, por isso seria legítimo o tom cômico naquela situação. Essa postagem, para alguns comentaristas, seria a defesa da liberdade de expressão ante 0 fundamentalismo religioso que dizimou a vida dos cartunistas em questão. No entanto, no texto do Sensacionalista são os politicamente corretos que entram em discussão, são eles o alvo da crítica. Assim, também alguns deles se manifestam nos comentários para defender a posição de que o humor deve ter limites, sim.

\section{Análise dos comentários com base nas recorrências evidenciadas}

A partir das observações que fizemos, a respeito da circulação de sentidos no espaço dos comentários, pudemos eleger categorias de análise que nos permitiram refletir sobre os procedimentos que alguns leitores utilizaram para fazer valer suas percepções sobre o conteúdo das postagens "LUTO: turistas em Paris estão tirando fotos a meio-pau de selfie" e "Massacre de Paris será feriado mundial do 'Dia do Limite do Humor", veiculadas no site Sensacionalista.

\section{a) Humor e cognição}

Nesta categoria, reunimos os comentários daqueles que não entendem 0 caráter humorístico do site e dos que se predispõem a explicá-lo aos demais leitores. Não apenas nas postagens que versam sobre a tragédia envolvendo os cartunistas do semanário satírico, mas também em várias outras, é comum existirem comentaristas que parecem não entender 0 conteúdo do site, levando "a sério" tudo o que leram. Diante disso, os leitores habituais do Sensacionalista rapidamente se mobilizam para esclarecer a que se propõe o site. Esses leitores frequentes apontam que, para além do riso despropositado, é objetivo do Sensacionalista também efetuar críticas sociais direcionadas a diversos públicos e grupos sociais. Por isso, tentam deixar claro que não seria intenção do site apenas fazer brincadeira com a tragédia, mas também efetuar alguma crítica social ou de costumes. Podemos verificar um pouco do movimento destes comentaristas a partir da reprodução dos comentários em torno das postagens em questã $0^{5}$ : 
- André Guigue diz:

Turistas brincando com a tragédia? Muito mau gosto.. senhores jornalistas da Sensacionalista autores desta "reportagem"!

- Rodrigo Tabosa em resposta a André Guigue diz:

Senhor, esse aqui é um jornal humorístico e todas as suas reportagens são fictícias. Exclusivamente feito por brincadeira. Como o próprio site diz: Isento de verdades.

Fonte: Comentários sobre a postagem "LUTO: turistas em Paris estão tirando fotos a meio-pau de selfie".

Esse primeiro comentário nos parece se tratar de uma ironia por parte do comentarista ao invés de incompreensão para com 0 conteúdo do site. Ela estaria expressa nas aspas da palavra reportagem. Mas a ironia é um recurso humorístico que precisa ser bem arquitetado para que seja compreendido pelo leitor, pois pode dar mais margem para 0 entendimento da mensagem de forma diferente da intencionalidade do emissor. Para Bergson (1983), o riso tem significação social e deve corresponder a algumas exigências da vida em comum. Ele 0 considera destinado à inteligência, entretanto, deve ter contato com outras inteligências para que atinja seu objetivo. 0 riso é resultado do entendimento imediato da mensagem e a resposta espontânea sem precisar de grandes explicações ao que foi compartilhado. 0 humor também pode ser expressão de senso crítico, traduzindo o conhecimento de quem produz o conteúdo e a capacidade de interpretação de quem o consome.

Muitos comentaristas parecem não entender a que se destina o site, também não conseguem perceber os efeitos de ironia e paródia utilizados nas postagens, e outros, por sua vez, criticam essa falta de compreensão e reclamam que isso evidencia déficit cognitivo por parte de certos internautas. Alguns leitores ocupam o espaço destinado aos comentários apenas para registrar o quanto se divertem lendo os registros de outros comentaristas que levam "a sério" o conteúdo dos posts. Assim, o riso da ingenuidade ou do déficit cognitivo prospera e resulta em relações de sociabilidades regidas pelo ato de falar pelo simples prazer de falar.

\section{b) Humor e tragédia}

A tragédia seria instrumento passível de comicidade? É em torno dessa questão que se organizam os comentários desta categoria. Como era de se esperar, postagens em tom crítico e humorístico a respeito de um atentado que dizimou a vida de doze pessoas não ficariam imunes às represálias por parte de alguns leitores. Desse modo, vários comentaristas questionam a validade das postagens diante da gravidade da tragédia, e outros justificam a pertinência delas, visto que o próprio semanário Charlie Hebdo também produzia humor com temas considerados tabus, como a religião. Assim, a questão do uso 
do humor em meio a uma situação de sofrimento humano gerou intensos debates, como os que reproduzimos a seguir:

- Marcos Correia diz:

piada infeliz em um momento triste. nem tudo é motivo para fazer piada.

- Gabriel Leonardo em reposta a Marcos

Correia diz:

Ta mais pra uma critica aos defensores do politicamente correto que pra uma piada.

- Felipe Accioly em resposta a Marcos

Correia diz:

Apoio a indicacao de sua suma sapiencia, Marcos correia para presidir a comissao que tera autoridade moral para estipular 0 devido limite a essa corja de humoristas. CORREIA NELES!!!

- Silvio Sérgio de Siqueira em resposta a

Marcos Correia diz:

acho que foi uma homenagem as vítimas que mesmo com as ameaças seguiram em frente defendendo 0 que acreditavam e a liberdade de expressão até as últimas consequências.

Todos os comentários reproduzidos anteriormente foram direcionados à postagem "Massacre de Paris será feriado mundial do 'Dia do Limite do Humor", que satiriza os defensores de limites para o humor, os chamados "politicamente corretos". 0 ponto de inflexão centra-se nos seguintes questionamentos: haveria limites para
0 cômico? E quem os imporia? Assim, o conteúdo do post ridiculariza as pessoas que julgam ser necessário estabelecer parâmetros sobre até que ponto o humor é aceitável. A partir disso, o site torna-se, então, alvo de críticas daqueles que não acham correto tratar de modo cômico um assunto tão delicado como um massacre, mesmo que 0 tom em maior evidência fosse 0 crítico.

No entanto, as pessoas que lançam críticas à postagem revelam não perceber nela esse tom crítico, como o comentarista Marcos Correia, que se refere ao conteúdo como sendo uma piada, que, para ele, não seria aceitável naquele momento de luto. Ora, piadas são recursos humorísticos que possuem como objetivo provocar risos naquele a quem se destina. Já o humor crítico teria como propósito a reflexão acerca de determinado assunto. Os que defendem o site apelam justamente para este argumento: o humor produzido ali pelo Sensacionalista teria a finalidade clara de instigar 0 leitor a pensar criticamente a respeito do assunto em pauta, que estava centrada na problemática definição sobre quais seriam os parâmetros aceitáveis para 0 humor e quem seria moralmente autorizado a estabelecê-los. 0 comentarista Marcos Correia reclama que aquela postagem seria uma piada (portanto, despropositada) de mau gosto, que não deveria ser colocada em um momento triste como aquele, ao que o internauta Felipe Accioly responde ironizando o comentarista por agir como alguém apto a presidir a suposta comissão que estabeleceria limites aos humoristas. Ao que parece, a questão do objetivo do humor se encontraria no 
âmago do debate. Se ele é entendido como uma piada sem propósito, logo não pode lançar mão da tragédia como instrumento de comicidade; mas se 0 mesmo é entendido como sendo crítico, como tendo um propósito relevante, então pode ser acionado, não importa do que se trate.

Nas teorias sobre 0 riso foram instituídas algumas discussões sobre a essência da comicidade. Por exemplo, é possível rir do homem em quase todas as manifestações. "Exceção feita ao domínio dos sofrimentos, coisa que Aristóteles já havia notado" (PROPP, 1992, p.29). Propp (1992) argumentava que podiam ser ridicularizados a aparência física das pessoas, seus desejos, suas debilidades cognitivas e pouca noção de senso comum. Enfim, segundo o autor, pode-se rir de tudo referente à vida física, à moral e ao intelecto dos homens. Só não é aceitável que a morte e a tragédia sejam instrumentos de comicidade. No entanto, na contemporaneidade não apenas 0 domínio dos sofrimentos seria alvo de discussão quanto a sua comicidade ou não, mas também a questão da aparência física, das minorias socialmente excluídas, dos marginalizados, etc. Em uma sociedade em que lutas simbólicas, pelo respeito ao outro em toda sua dimensão humana, estão a todo tempo sendo travadas, não somente a tragédia e 0 sofrimento, bem como todas as manifestações humanas passam a se tornar objeto de reflexão social quanto à sua risibilidade ou não.

Esses comentários críticos são os mais frequentes e também os que mais repercutem entre os leitores assíduos do Sensacionalista, os quais se veem impelidos a defender 0 site. Alguns dos que concordaram e se divertiram com as "matérias" postaram seus comentários, sem, contudo, conseguir mobilizar muitas interações. Nesse caso, confirma-se a premissa de que 0 conflito é um importante fator de sociação nas relações online, principalmente em mídias do tipo broadcast, em que as mensagens são inicialmente transmitidas de um para muitos, e esses muitos, que normalmente são desconhecidos entre si e encontram-se geograficamente espalhados, congregam-se para discutir o assunto posto em pauta, sem temor de adentrar 0 espectro conflitivo. Isso não, necessariamente, se constitui como algo negativo, como já havia presumido Simmel (1983), visto que é mediante a mobilização de argumentos discordantes que sentidos diversos sobre 0 caso são acionados e leituras diferentes sobre as postagens podem ser exploradas.

\section{c) Limites para o humor?}

\section{Entre 0 riso $\mathrm{e} o$ respeito às religiões}

Nesta categoria, despontam os comentários que perscrutam o tipo de humor feito pelo satírico jornal Charlie Hebdo. A maioria das discussões é iniciada por aqueles que não concordam com 0 tom acidamente cômico com que eram retratados os mulçumanos, a religião islã e seus objetos de culto. Em resposta a esses, despontam comentários que defendem 0 direito de se expressar livremente, independentemente 
de qual seja 0 assunto em pauta. Seguem alguns comentários em torno da questão:

- Tiago Pinto diz:

[...] Estes cartunistas assassinados agrediram o povo muçulmano durante anos, com as suas piadas politicamente incorretas. 0 que culminou no aparecimento de verdadeiros assassinos que praticaram esta barbárie. Agora cabe uma reflexão: "Será que a dor que o povo francês está sentindo agora é maior do que a dor acumulada durante anos pelo povo muçulmano, sendo alvo da liberdade, igualdade e 'fraternidade' das piadas sem limites do povo francês? [...]".

- Michael Nienow diz:

Achei a escolha do fato bem desnecessário pra criticar os politicamente corretos, é fácil falar de liberdade de humor quando não se é alvo de piadas que pode cutucar um fato doloroso na vida de alguém, defensores do humor livre, pensem, só porque vocês levam todas as piadas na esportiva, nem todos conseguem.

Fonte: Comentários sobre a postagem "Massacre de Paris será feriado mundial do 'Dia do Limite do Humor'".

A maioria dos comentários que tangenciam a questão do humor feito pelo Charlie Hebdo traz como argumento a ideia de que a comicidade proposta pelo semanário teria se transformado em agressão contra o povo muçulmano e seu sistema de crenças. Apelam para o senso de empatia do outro, ao interpelá-lo a tentar levar em conta 0 sofrimento causado aos fiéis do islamismo por terem seus objetos de culto sendo, repetidamente, alvo de zombarias. No entanto, há também aqueles que defendem com afinco o humor sem limitações, sem necessidade de tratar com respeito religião alguma, para que assim pudesse, livremente, conduzir ao riso e, através dele, à reflexão.

Sobre a liberdade de expressão, a qual também deve ser um caminho a ser explorado como aparato conceitual dessa empiria, pois, certamente, surgirá na inflexão, refletimos que se trata de um conceito, criado por Stuart Mill (1964) em 1859, que continua valendo porque não é algo que difira dos interesses dos indivíduos que vivem em comunidade. Livre expressão, respeito à diferença, diversidade e direitos iguais são axiomas que pertencem à mesma ordem de conceitos. A pluralização nasce do múltiplo (nas diferenças dos indivíduos e dos grupos). São vários os grupos sociais que se diferenciam na comunidade. E como a esfera pública plural se manifesta sobre a dicotomia entre liberdade de expressão e liberdade de opinião publicada pelo produtor de notícias para imprimir sentido à sua forma simbólica? E sobre 0 agenciamento da moral em relatos e narrativas de acontecimentos sociais que privilegiam o dolo, a culpa e 0 sofrimento social para não se confrontar com a diversidade de atores, opiniões, doutrinas ou ideologias? Essas são questões que problematizam a empiria, mas que precisam ser mais bem desenvolvidas.

Para complementar a inflexão, façamos uma breve revisão histórica sobre a relação entre riso e religiosidade ao longo dos séculos. Na Idade Antiga, o cristianismo primitivo já considerava 0 
riso condenável. Sobre isso, Bakhtin (2010, p.63) cita Reich (1903, p.116) que enuncia: "São João Crisóstomo declara de saída que as burlas e 0 riso não provêm de Deus, mas são uma emanação do diabo; 0 cristão deve conservar uma seriedade constante, 0 arrependimento e a dor em expiação de seus pecados".

Na Idade Média, o riso ainda era uma manifestação reprovada pela igreja, uma faculdade do homem que 0 distanciava de Deus. 0 riso era considerado um sacrilégio e o sério visto como a expressão do bem, da verdade, do que deveria ser considerado importante e digno de atenção. No entanto, Bakhtin (2010) conta que, em compensação, a Idade Média conferiu ao cômico privilégios excepcionais de licença e impunidade fora dos templos, ou seja, nas praças públicas, nas festas populares e na literatura recreativa. Justamente esse caráter proibido, que o colocava fora dos circuitos institucionais e formais da vida e das ideias, fazia com que 0 riso pudesse irromper com um radicalismo e liberdade excepcionais. Contudo, em sua passagem para o Renascimento, o riso passa do estado de existência proibida e espontânea para se constituir em expressão da consciência crítica, livre e histórica da sua época (BAKHTIN, 2010). Sendo assim, a partir do Renascimento, concebeu-se a ideia de que somente 0 riso poderia ter acesso a certos assuntos importantes do mundo. Talvez seja esse 0 caso da religião.

Desse modo, a ideia que surge em muitos dos comentários favoráveis ao humor praticado pelo
Charlie Hebdo e pelo Sensacionalista é de que 0 humor é o único campo da vida em sociedade que teria, de fato, licença para "dizer o que quiser". Somente ele poderia "desmascarar" os sistemas de opressão social, fossem religiosos ou morais. E esse poder não lhes poderia ser tirado. Assim, conforme exposto aqui, 0 debate sobre 0 riso e 0 sagrado perpassa, de forma complexa, a história das narrativas e se coloca até hoje como inconsensual.

\section{Conclusão (...) Ao sabor do riso}

Além da complexidade dos sentidos, sentimentos acionados e das dinâmicas de sociações tratadas, inferimos que a discordância é a que, normalmente, produz o maior número de comentários no caso analisado. Essa é a motivação do estar juntos nas respostas endereçadas às postagens do Sensacionalista com relação a a atentado contra o Charlie Hebdo. Além disso, é possível afirmar que são raros os movimentos em direção à abertura para a mudança de opiniões - 0 que ocorre não apenas no caso estudado, mas também em comentários de vários outros espaços online. Contudo, destacamos que, nas conversações informais, construídas em espaços como 0 site Sensacionalista, os comentaristas podem até ter 0 fetiche da afirmação, mas, ainda assim, são impelidos a olhar para uma mesma questão sob pontos de vista diversos.

Uma das consequências das conversações online, segundo o corpus aqui analisado, é que 
aparecem bifurcações na produção de sentidos, segundo enunciações que especificam duplas narrativas sobre um mesmo tema. Se alguns sujeitos interpretam o site como verdadeiro, eles sobrecarregam seus comentários com tintas moralistas sobre 0 viés humorístico adotado na interpretação dos acontecimentos. Quando concordam com a mentira ou paródia sobre 0 acontecimento, eles exacerbam na profanação da tragédia. Em ambos os casos, estabelecem a discórdia e reafirmam o fenômeno do conflito, o qual, por vezes, sustenta-se em função de si mesmo (SIMMEL, 1983).

Desse modo, inferimos que os comentários em sites de humor ou de notícias permitem 0 desdobramento das narrativas propostas, sejam as profanas ou as que se sustentam na linearidade da cobertura jornalística tradicional. Nesse sentido, um dos principais desdobramentos, a nosso ver, estaria circunscrito à questão da possibilidade de impor ou não limites para 0 humor - tratando-se de tragédias ou religião. 0 argumento, em ambos os casos, parece estar centrado no propósito do humor posto em pauta. 0 riso, abordando tragédias ou crenças alheias, que parece ser evocado apenas com 0 propósito de entretenimento sociável, não se torna aceito por muitos. Mas, se esse mesmo riso estiver desprendido do caráter de sociabilidade, demonstrando, assim, um "propósito maior", que seria a crítica ou reflexão, então terá mais chances de ser bem aceito. Porque, como mencionado no início da análise, o riso resulta da compreensão imediata da mensagem. 0 humor, para ser efetivo, precisa ter a capacidade de alinhar o contato entre as inteligências, de modo que não haja espaço, demasiadamente amplo, para choques interpretativos resultantes de visões diferentes.

Dessa forma, percebe-se que a indignação éticomoral de alguns internautas é impulsionada por esse desvio, entre a intencionalidade de quem produz o humor e os sentidos despertados naqueles que são tocados por ele. 0 universo de valores suscitado por alguns dos comentaristas busca chamar a atenção para o fato de que, nas relações sociais, proliferam experiências que mostram que o sabor do riso pode ser bastante amargo para inúmeros sujeitos e grupos. A justificativa do "isso é apenas uma piada" ou "eu só estava brincando" não convence quando pessoas se sentem atacadas em sua fé ou naquilo que elas enxergam como sagrado. Destarte, o Dicionário Michaelis da Língua Portuguesa descreve o sagrado como sendo, entre outras coisas, aquilo "que, pelas suas qualidades ou destino, merece respeito profundo e veneração absoluta". A religião e a tragédia, para muitos comentaristas do site, parecem fazer parte desse conjunto de coisas que estão separadas do mundo comum e que devem ser abordadas apenas de forma ritualística, em respeito ao outro que se sente tocado por elas.

Por fim, parafraseamos Sodré (2006), que salienta a emergência de comunidades afetivas, com base estética, nas quais as paixões dos sujeitos mobilizam a discursividade das interações. 
Para além da assertiva de que 0 estar juntos em redes sociotécnicas é uma experiência cognitiva e social, os comentaristas do site Sensacionalista demonstram que a experiência pode despertar emoções, críticas, indignação e a revisão de normas e valores sociais através do riso. Suas postagens permanecem, de alguma forma, na topografia do jornalismo, provocando complexas interrogações às suas operações de leiturabilidade. As redes sociodigitais produzem um circuito comunicativo multidirecional, que permite novos desafios para a reflexão sobre 0 acontecimento. E o riso também contribui para a compreensão das diferentes narrativas que se ancoram na realidade e criam novos sentidos na sociedade contemporânea.

\section{Referências}

BAKHTIN, Mikhail Mikhailovich. A Cultura Popular na Idade Média e no Renascimento: 0 contexto de François Rabelais. $7^{\mathrm{a}}$ ed. São Paulo: HUCITEC; Brasília: Editora da Universidade de Brasília, 2010.

BERGSON, Henri. 0 riso: ensaio sobre a significação do cômico. Rio de Janeiro: Zahar Editores, 1983.

BRAGA, A. A. RODRIGUES, A. D. Análises do Discurso e Abordagem Etnometodológica do Discurso. In: ENCONTRO ANUAL DA COMPÓS, 23, 2014, Belém. Anais... Belém: Compós, 2014. P.1-19.

L. LANA. Luto: turistas em Paris estão tirando fotos a meio-pau de selfie. Sensacionalista. 08, jan. 2015 (Online). Disponível em: < http://sensacionalista.uol. com.br/2015/01/08/luto-turistas-em-paris-estao-tirandofotos-a-meio-pau-de-selfie/> . Acesso em 20 jan. 2015.

MAFFESOLI, Michel. 0 tempo das tribos: 0 declínio do individualismo nas sociedades de massa. $3^{\text {a }}$ ed. Rio de Janeiro: Forense-Universitária, 2000.

MILL, Stuart John. Ensaio sobre a Liberdade. Lisboa: Arcádia, 1964.

PROPP, Vladímir. Comicidade e riso. São Paulo: Editora Ática, 1992.

SENNET, Richard. Juntos: os rituais, os prazeres e a política da cooperação. Rio de Janeiro: Record, 2012.

SENSACIONALISTA. Massacre de Paris será feriado mundial do 'Dia do Limite do Humor'. 07, jan. 2015 (Online). Disponível em: < http://sensacionalista.uol.com. br/2015/01/07/massacre-de-paris-sera-feriado-mundial-dodia-dolimite-do-humor/>. Acesso em 20 jan. 2015.

SIMMEL, Georg. Questões fundamentais da sociologia: indivíduo e sociedade. Rio de Janeiro: Zahar, 2006.

. A natureza sociológica do conflito. In: Moraes Filho, Evaristo (org.). Simmel. São Paulo, Ática, 1983. SODRÉ, Muniz. As Estratégias Sensíveis: Afeto, Mídia e Política. Petrópolis: Vozes, 2006. 
Mediated feelings:

\section{Sensacionalista produces laugh narratives and disagreement about the Charlie Hebdo Case}

\section{Abstract}

This article reflects the argumentative constructs in the Sensacionalista humorous site about the tragedy suffered by the satirical French newspaper Charlie Hebdo on 07 January 2015. The tragic event resulted in several debates about laugh narratives. Thus, the corpus comes at a qualitative research, focusing mainly on the observation of comments in two Sensacionalista posts about the topic. Concludes that the bifurcations in the meaning production journalistic reports of events associated with the emotions, humor, hate and cognitive estrangement - allow the circulation of multiple narratives about the same topic and that the sociation presented in conflict disagreement or sociability among peers.

\section{Keywords}

Senses Bifurcation. Sensacionalista. Charlie Hebdo.

\section{Sentimientos mediados:}

\section{Sensacionalista produce narrativas} de risa y discordancias sobre el Caso Charlie Hebdo

\section{Resumen}

El texto refleja construcciones argumentativas del sitio web humorístico Sensacionalista sobre la tragedia sufrida por el diario satírico francés Charlie Hebdo en enero de 2015. Acontecimiento trágico que dio lugar a una serie de reflexiones sobre las narrativas humorísticas. Por lo tanto, el corpus se compone de una investigación cualitativa, centrándose principalmente en la observación de los comentarios en dos publicaciones del Sensacionalista sobre el asunto. Se concluye que las bifurcaciones en la producción de significados - relato periodístico asociado con las emociones, el humor, el odio y las discrepancias cognitivas permiten la circulación de diferentes narrativas sobre un mismo tema y que la sociación se presenta en el desacuerdo o en la sociabilidad entre pares.

\section{Palabras clave}

Bifurcación de significados. Sensacionalista.

Charlie Hebdo. 


\section{Expediente}

A revista E-Compós é a publicação científica em formato eletrônico da Associação Nacional dos Programas de Pós-Graduação em Comunicação (Compós). Lançada em 2004, tem como principal finalidade difundir a produção acadêmica de pesquisadores da área de Comunicação, inseridos em instituições do Brasil e do exterior.

\section{E-COMPÓS I www.e-compos.org.br I E-ISSN 1808-2599}

Revista da Associação Nacional dos Programas de Pós-Graduação em Comunicação.

Brasília, v.19, n.1, jan./abr. 2016.

A identificação das edições, a partir de 2008, passa a ser volume anual com três números.

Indexada por Latindex I www.latindex.unam.mx

\section{CONSELHO EDITORIAL}

Alexandre Farbiarz, Universidade Federal Fluminense, Brasil Alexandre Rocha da Silva, Universidade Federal do Rio Grande do Sul, Brasil Ana Carolina Damboriarena Escosteguy, Pontifícia Universidade Católica do Rio Grande do Sul, Brasil

Ana Carolina Rocha Pessôa Temer, Universidade Federal de Goiás, Brasil Ana Regina Barros Rego Leal, Universidade Federal do Piaú, Brasil Andrea França, Pontifícia Universidade Católica do Rio de Janeiro, Brasil André Luiz Martins Lemos, Universidade Federal da Bahia, Brasil Antonio Carlos Hohlfeldt, Pontifícia Universidade Católica do Rio Grande do Sul, Brasil

Arthur Ituassu, Pontifícia Universidade Católica do Rio de Janeiro, Brasil Álvaro Larangeira, Universidade Tuiuti do Paraná, Brasil

Ângela Freire Prysthon, Universidade Federal de Pernambuco, Brasil César Geraldo Guimarães, Universidade Federal de Minas Gerais, Brasil Cláudio Novaes Pinto Coelho, Faculdade Cásper Líbero, Brasil Daisi Irmgard Vogel, Universidade Federal de Santa Catarina, Brasil Denize Correa Araujo, Universidade Tuiuti do Paraná, Brasil Eduardo Antonio de Jesus, Pontifícia Universidade Católica de Minas Gerais, Brasil

Daniela Zanetti, Universidade Federal do Espirito Santo, Brasil Eduardo Vicente, Universidade de São Paulo, Brasil Elizabeth Moraes Gonçalves, Universidade Metodista de São Paulo, Brasil Erick Felinto de Oliveira, Universidade do Estado do Rio de Janeiro, Brasil Francisco Elinaldo Teixeira, Universidade Estadual de Campinas, Brasil Francisco Paulo Jamil Almeida Marques, Universidade Federal do Paraná, Brasil

Gabriela Reinaldo, Universidade Federal do Ceará, Brasil Goiamérico Felício Carneiro Santos, Universidade Federal de Goiás, Brasil Gustavo Daudt Fischer, Universidade do Vale do Rio dos Sinos, Brasil Herom Vargas, Universidade Municipal de São Caetano do Sul, Brasil Itania Maria Mota Gomes, Universidade Federal da Bahia, Brasil
Janice Caiafa, Universidade Federal do Rio de Janeiro, Brasil Jiani Adriana Bonin, Universidade do Vale do Rio dos Sinos, Brasil José Afonso da Silva Junior, Universidade Federal de Pernambuco, Brasil José Luiz Aidar Prado, Pontifícia Universidade Católica de São Paulo, Brasil Juçara Gorski Brittes, Universidade Federal de Ouro Preto, Brasil Kati Caetano, Universidade Tuiuti do Paraná, Brasil Lilian Cristina Monteiro França, Universidade Federal de Sergipe, Brasil Liziane Soares Guazina, Universidade de Brasilia, Brasil Luíza Mônica Assis da Silva, Universidade de Caxias do Sul, Brasil Luciana Miranda Costa, Universidade Federal do Pará, Brasil Malena Segura Contrera, Universidade Paulista, Brasil Maria Ogécia Drigo, Universidade de Sorocaba, Brasil Maria Ataide Malcher, Universidade Federal do Pará, Brasil Marcia Tondato, Escola Superior de Propaganda e Marketing, Brasil Marcel Vieira Barreto Silva, Universidade Federal da Paraíba, Brasil Maria Clotilde Perez Rodrigues, Universidade de São Paulo, Brasil Maria das Graças Pinto Coelho, Universidade Federal do Rio Grande do Norte, Brasil

Mauricio Ribeiro da Silva, Universidade Paulista, Brasil

Mauro de Souza Ventura, Universidade Estadual Paulista, Brasil Márcio Souza Gonçalves, Universidade do Estado do Rio de Janeiro, Brasil Micael Maiolino Herschmann, Universidade Federal do Rio de Janeiro, Brasil Mirna Feitoza Pereira, Universidade Federal do Amazonas, Brasil Nísia Martins Rosario, Universidade Federal do Rio Grande do Sul, Brasil Potiguara Mendes Silveira Jr, Universidade Federal de Juiz de Fora, Brasil Regiane Regina Ribeiro, Universidade Federal do Paraná, Brasil Rogério Ferraraz, Universidade Anhembi Morumbi, Brasil Rose Melo Rocha, Escola Superior de Propaganda e Marketing, Brasil Rozinaldo Antonio Miani, Universidade Estadual de Londrina, Brasil Sérgio Luiz Gadini, Universidade Estadual de Ponta Grossa, Brasil Simone Maria Andrade Pereira de Sá, Universidade Federal Fluminense, Brasil Veneza Mayora Ronsini, Universidade Federal de Santa Maria, Brasil Walmir Albuquerque Barbosa, Universidade Federal do Amazonas, Brasil

\section{COMISSÃO EDITORIAL}

Cristiane Freitas Gutfreind, Pontifícia Universidade Católica do Rio Grande do Sul, Brasil Irene Machado, Universidade de São Paulo, Brasil

Eduardo Antonio de Jesus, Universidade Católica de Minas Gerais, Brasil

\section{CONSULTORES AD HOC}

Cleusa M. Andrade Scroferneker, Pontifícia Universidade Católica do Rio Grande do Sul, Brasil Francisco Rüdiger, Pontifícia Universidade Católica do Rio Grande do Sul, Brasil Juliana Freire Gutmann, Universidade Federal da Bahia, Brasil

Karla Regina M. P. Patriota Bronsztein, Universidade Federal de Pernambuco, Brasil Laura Loguercio Cánepa, Universidade Anhembi Morumbi, Brasil Lucia Isaltina C. Leão, Pontifícia Universidade Católica de São Paulo, Brasil

\section{EQUIPE TÉCNICA}

\section{ASSISTENTE EDITORIAL I Márcio Zanetti Negrini}

REVISÃO DE TEXTOS I Press Revisão

EDITORAÇÃO ELETRÔNICA I Roka Estúdio

CONTATO I revistaecompos@gmail.com

\section{COMPÓS I www.compos.org.br}

Associação Nacional dos Programas de Pós-Graduação em Comunicação

\section{Presidente}

Edson Fernando Dalmonte

Programa de Pós-Graduação em Comunicação

e Cultura Contemporânea - UFBA

edsondalmonte@uol.com.br

\section{Vice-presidente}

Cristiane Freitas Gutfreind

Programa de Pós-Graduação em Comunicação Social - PUC-RS cristianefreitas@pucrs.br

Secretário-Geral

Rogério Ferraraz

Programa de Pós-Graduação em Comunicação

Universidade Anhembi Morumbi

rogerioferraraz@anhembimorumbi.edu.br 